\title{
APONTAMENTOS JURÍDICOS DA SUSTENTABILIDADE EMPRESARIAL SOCIOAMBIENTAL
}

\author{
LEGAL ELEMENTS OF SOCIAL AND ENVIRONMENTAL BUSINESS \\ SUSTAINABILITY
}

Luiz Dario dos SANTOS ${ }^{1}$

ISSUE DOI: $10.21207 / 1983.4225 .576$

\begin{abstract}
RESUMO
Este artigo tem o objetivo de discutir alguns pontos jurídicos relevantes que estão inseridos no ambiente da sustentabilidade empresarial contemporânea. Neste prisma, o presente estudo apresentará a concretização da legislação constitucional e infraconstitucional quanto à necessária proteção do meio ambiente saudável e da prática da responsabilidade socioambiental empresarial.
\end{abstract}

Palavras Chave: Sustentabilidade, Socioambiental, Empresa.

\section{ABSTRACT}

This paper aims to discuss some relevant legal points that are inserted in the environment of contemporary business sustainability. In this perspective, the present study will present the implementation of

\footnotetext{
${ }^{1}$ Advogado. Pós-Doutor em Democracia e Direitos Humanos pela Universidade de Coimbra - Portugal. Doutor em Direito do Consumidor pela UNIMES - Santos/SP, Mestre em Biodireito, Ética e Cidadania pelo Centro UNISAL - Lorena/SP, Especialista em: Educação a Distância: Planejamento, Implantação e Gestão, Direito do Consumidor, Direitos Humanos e Gestão Ambiental pelo Centro Universitário Claretiano/SP, Direito Ambiental/Urbanístico e Direito Constitucional pela UniAnhanguera - Uniderp/SP, Direito Processual Civil pelo UniFMU/SP, Direito do Trabalho e Educação Ambiental pela Unicid/SP. Professor da Graduação e Pós Graduação (Presencial e EaD) da Universidade Santo Amaro UNISA/SP. Avenida de Pinedo, 126 - Capela do Socorro - Santo Amaro - SP . CEP 04764000. Email: luizdario@uol.com.br
} 
constitutional and infraconstitutional legislation regarding the necessary protection of the healthy environment and the practice of corporate social and environmental responsibility.

Keywords: Sustainability, Socio-environmental, Company.

\section{INTRODUÇÃO}

Com o surgimento da sociedade de consumo, que se formou, principalmente, a partir da segunda metade do século XX, fez com que houvesse mudanças comportamentais das empresas e dos consumidores, com vários impactos ao meio ambiente.

A atuação do capitalismo e a ordem econômica traduzem na essência a exploração para a obtenção de vantagem econômica (lucro), todavia, o que se deve entender é o uso, acima de tudo, da chamada sustentabilidade, ou seja, o equilíbrio entre as questões econômicas e o manuseio do meio ambiente.

Discutiremos, neste estudo, a importância de um consumo sustentável por parte de todos da sociedade, em especial as pessoas jurídicas, com a prática da responsabilidade socioambiental empresarial.

\section{CONSIDERAÇÕES SOBRE A TEMÁTICA "SUSTENTABILIDADE"}

A intenção de construir um planeta melhor para todas as pessoas sem lesar o meio ambiente é uma meta social a ser alcançada por todos. Sabemos que não é uma tarefa fácil, mas é possível com a mobilização das nações no mundo todo.

O exercício da sustentabilidade funda-se na ideia de que a capacidade de exploração da Terra não poderá ser extrapolada sem que aconteçam grandes fenômenos ambientais, econômicos e sociais.

Podemos dizer "na prática", que o conceito de sustentabilidade representa promover a exploração de áreas ou o uso de recursos planetários (naturais ou não) de forma a prejudicar o menos possível o equilíbrio entre o meio ambiente e as comunidades humanas e toda a biosfera que dele dependem para existir. No entanto, não é bem assim. (Fonte: http://www.atitudessustentaveis.com.br/sustentabilidade/sustentabilidade/. Acessado em: 16 jul. 2017). 
A construção de um conceito de sustentabilidade vem sendo realizado, especialmente, a partir da década de 70, com a realização de vários encontros mundiais (de proteção ao meio ambiente) promovidos pela ONU (Organização das Nações Unidas). Para conhecimento, seguem alguns deles: Estocolmo/72, Eco/92 ou Rio/92, Rio+10 (em 2002) e o Rio+20 (em 2012).

Vamos, agora, analisar a melhor doutrina que estuda o conceito de sustentabilidade?

Podemos conceituar sustentabilidade como uma forma inteligente de manipular o meio ambiente, a economia e a sociedade, de maneira a garantir um mínimo de qualidade de vida para as atuais e futuras gerações.

$\mathrm{Na}$ linha de raciocínio de Celso Funcia Lemme (2010, p. 41), a crescente consciência e fiscalização pela sociedade têm: "[...] levado ao surgimento de novas leis e padrões, requerendo posturas estratégicas adequadas para lidar com as novas regras do jogo". Trata-se, neste caso, de uma exigência de mercado e dos consumidores, onde a prática da "sustentabilidade" se faz presente nas suas diferentes dimensões e estratégias empresariais.

Agora, ampliando e reforçando estas referidas ideias, Takeshy Tachizawa \& Rui Otávio Bernardes de Andrade (2012, p. 24) tratam da contextualização da sustentabilidade, considerando como:

[...] uma conjugação equilibrada da busca da rentabilidade com a consecução de metas ambiciosas de ecoeficiência, e de valorização dos seus colaboradores, bem como o aprimoramento da interação da companhia com as comunidades que abrigam suas instalações e com todas as demais partes interessadas.

Nota-se, aqui, uma preocupação global, em que seus principais personagens devem se atentar com as dimensões ambientais, econômicas e sociais, para se garantir um mínimo de qualidade e segurança.

Conclui-se que a presente geração tem o dever de preservar as condições inerentes ao meio ambiente, não só para si, como também para as futuras gerações, sob pena de pagar um preço muito alto pelas nossas ações e omissões. 


\subsection{OBJETIVOS DE SUSTENTABILIDADE (DESENVOLVIMENTO SUSTENTÁVEL)}

De acordo com este "Relatório Brundland", o desenvolvimento sustentável deve ser uma agenda integrada para se alcançar resultados nas dimensões ambientais, econômicas e sociais, sendo que sua força estaria na sintonia (entrelaçamento) dessas dimensões.

Entende-se que, os seis elementos essenciais dos objetivos do desenvolvimento sustentável, segundo José Carlos Barbieri \& Jorge Emanuel Reis Cajazeira (2016, p. 131), são os seguintes:

- Dignidade: para lutar contra a pobreza e a iniquidade;

- Justiça: para promover sociedades seguras e pacificas e instituições fortes;

- Parceria: para catalisar a solidariedade em prol do desenvolvimento sustentável;

- Pessoas: para garantir vidas saudáveis, conhecimento e inclusão de homens e mulheres;

- Planeta: para proteger os ecossistemas para todas as sociedades;

- Prosperidade: para o crescimento de uma economia forte, inclusiva e transformadora.

Note que estes objetivos representam um grande dimensionamento de metas e finalidades, nas esferas ambientais, econômicas e sociais. Só que há um importante detalhe a se considerar: "É possível afirmar sobre sua efetiva aplicabilidade em relação às esferas mencionadas?" Tenho certeza de que esta questão é de complexa resolução.

\subsection{A APLICABILIDADE DA SUSTENTABILIDADE COMO EXEMPLO PARA O SÉCULO XXI}

A sociedade contemporânea passa por fortes mudanças, sendo que uma das grandes preocupações é a relação entre o ser humano e o ambiente que ele habita e explora para o seu bem-estar.

Neste contexto, portanto, está a sustentabilidade, na qual Juarez Freitas (2012, p. 15) demonstra uma atenção e preocupação toda especial, quando afirma que: "A sustentabilidade, numa fórmula sintética, consiste 
em assegurar, de forma inédita, as condições propícias ao bem-estar físico e psíquico no presente, sem empobrecer e inviabilizar o bem-estar do amanhã, $[\ldots] ”$.

A sustentabilidade está relacionada, então, a diferentes posições e visões entre si e no saber de Reinaldo Dias (2015, p. 14), a sustentabilidade eficiente envolve várias atitudes, tais como:

- Exploração dos recursos minerais (petróleo, carvão, minérios) de forma controlada, racionalizada e com planejamento;

- Uso de fontes de energia limpas e renováveis (eólica, geotérmica e hidráulica) para diminuir o consumo de combustíveis fósseis;

- Criação de atitudes pessoais e empresariais voltadas para a reciclagem de resíduos sólidos. Esta ação, além de gerar renda e diminuir a quantidade de lixo no solo, possibilita a diminuição da retirada de recursos minerais do solo;

- Desenvolvimento da gestão sustentável nas empresas para diminuir o desperdício de matériaprima e desenvolvimento de produtos com baixo consumo de energia.

Estas são atitudes indispensáveis, no cenário contemporâneo, para a prática de um novo paradigma ambiental, sem o qual estaremos fadados a sofrer consequências inimagináveis. Não há mais volta: ou reestruturamos para um novo modelo de consumo planetário ou seremos vítimas das nossas próprias ações e omissões.

\subsection{CLASSIFICAÇÃO DE SUSTENTABILIDADE}

A doutrina majoritária tem difundido o estudo da "sustentabilidade" no formato de um tripé, sendo assim, vamos conhecer, um pouco mais, das dimensões ambientais, econômicas e sociais?

\subsubsection{SUSTENTABILIDADE AMBIENTAL}


Busca-se, com a dimensão ambiental da sustentabilidade, o direito das gerações atuais, sem prejuízo das futuras, ao ambiente limpo, em todos os aspectos (meio economicamente equilibrado, como diz o artigo 225 da Constituição Federal de 1988).

ental"?

Mas, afinal, como podemos conceituar "Sustentabilidade Ambi-

É a capacidade de manter o ambiente natural viável à manutenção das condições de vida para as pessoas e para as outras espécies. Isso garante, ainda, a qualidade de vida para o homem, tendo em conta a habitabilidade, a beleza do ambiente e sua função como fonte de energias renováveis. A adoção das medidas que deem sustentação ambiental garante, em médio e longo prazo, um planeta em boas condições para o desenvolvimento das diversas formas de vida, inclusive a humana, garantindo a manutenção dos recursos naturais (florestas, matas, rios, lagos, oceanos) necessários para a qualidade de vida das próximas gerações. (Fonte: http://www. atitudessustentaveis.com.br/artigos/sustentabilidade-ambiental-desenvolvimento-e-protecao/. Acessado em: 17 jul. 2017).

Denota este conceito, a plena preocupação de proteger os recursos naturais do planeta, mas sem se esquivar de proporcionar uma sadia qualidade de vida aos seres animais e humanos.

Da mesma forma, entende-se por sustentabilidade ambiental a capacidade que:

[...] o meio ambiente tem de prover condições de vida favoráveis às pessoas e aos demais seres vivos, tanto no presente, como nas gerações futuras. Para garantir o desenvolvimento sustentável não basta apenas preservar o meio ambiente, é necessário haver crescimento econômico consciente e a promoção humana, através da sustentabilidade econômica e social, que juntamente com a sustentabilidade ambiental compõe o ideal sistêmico que denominamos sustentabilidade. (Fonte: http:// www.pensamentoverde.com.br/meioambiente/conceito-e-definicao-de-sustentabili dadeambiental/. Acessado em: 17 jul. 2017).

Deste conceito, pode-se concluir que é possível uma postura efetiva de proteção, gestão e manejo sustentável do meio ambiente? 
Neste caso, as pessoas físicas e jurídicas não têm outra opção, em razão do alto grau de exploração do ambiente (artificial, natural, cultural e do trabalho), senão a da prática inteligente e inteligente da sustentabilidade.

De qualquer maneira, observe alguns exemplos importantes de ações sustentáveis:

- Exploração dos recursos vegetais de florestas e matas, garantindo o replantio;

- Preservação de áreas verdes não destinadas à exploração econômica;

- Uso de fontes de energia limpas e renováveis (eólica, geotérmica e hidráulica);

- Reciclagem dos resíduos sólidos e exploração do gás liberado em aterros sanitários como fonte de energia;

- Consumo controlado da água, visando evitar o desperdício, além da assunção de medidas que visem a não poluição dos recursos hídricos; entre outras. (Fonte: http://www.atitudessustentaveis.com.br/artigos/sustentabilidade-ambientaldesenvol vimento-e-protecao/. Acessado em: 17 jul. 2017).

Portanto, a sustentabilidade ambiental é uma característica inerente a todo indivíduo ou instituição que tenha uma real e concreta preocupação com a sequência e longevidade da vida no planeta!

\subsubsection{SUSTENTABILIDADE ECONÔMICA}

Com as transformações da chamada "Sociedade de Consumo" (a partir de meados do século XX) e preocupados em estabelecer os preceitos constitucionais relacionados com a ordem econômica e a proteção do consumidor, os legisladores federais estabeleceram, essencialmente, dois artigos que versam sobre estes assuntos, ou seja, os artigos 170 e 225 da Constituição Federal de 1988.

Observe que este referido artigo 170 busca atender a harmonização entre o capitalismo e a preservação ambiental, para as presentes e futuras gerações. Vale dizer, neste momento, o que pensa Celso Antônio Pacheco Fiorillo (2017, p. 36), quando afirma que: "Busca-se, na 
verdade, a coexistência de ambos sem que a ordem econômica inviabilize um meio ambiente ecologicamente equilibrado e sem que este obste o desenvolvimento econômico".

Consagra-se, assim, uma economia de mercado, de natureza capitalista, porém, dando prioridade aos valores do trabalho humano e da livre iniciativa com vistas a alcançar o equilíbrio entre a justiça social, a defesa do meio ambiente e do consumidor.

Nesta linha de raciocínio, Jeaneth Nunes Stefaniak (2016, p. 78) nos alerta quando declara que a sustentabilidade como um:

[...] princípio ambiental que veio permear o debate acerca dos rumos da humanidade, especialmente sob a ótica econômica, através da adoção de medidas que viabilizem a continuidade do desenvolvimento econômico, porém de forma que se promova a preservação ecológica.

E para atender às necessidades jurídicas da "Sociedade de Consumo", foi criada a Lei n ${ }^{\circ} 8.078 / 90$, que instituiu o Código de Defesa do Consumidor (CDC), entrando em vigor em 11 de março de 1991, regulamentando não somente o artigo 48 do ADCT (Ato das Disposições Constitucionais Transitórias), mas principalmente o já citado artigo 170, da Constituição Federal de 1988.

Entenda que, se houver apenas o objetivo econômico, no âmbito empresarial, a sustentabilidade não prevalecerá, em especial, nas questões ambientais, pois serão desconsiderados e deixados de lado aqueles direitos preservacionistas ligados ao meio ambiente equilibrado.

\subsubsection{SUSTENTABILIDADE SOCIAL}

A sustentabilidade social tem como base um conjunto de atos que objetivam beneficiar e melhorar a "qualidade de vida" das pessoas, com vistas a minimizar as desigualdades sociais e fortalecer o pleno exercício da cidadania.

Um exemplo, que retrata muito bem os seus benefícios, é aquele em que se implanta um projeto educacional eficiente, diminuindo, assim, por exemplo, o índice de atos delituosos. Um caso de destaque foi a criação da Fundação Cafu, por parte do ex-jogador de futebol que dá o nome ao 
instituto. Ela está localizada no extremo sul da cidade de São Paulo, mais precisamente no Jardim Irene, uma região carente de serviços sociais públicos, além de um alto índice de criminalidade.

E além de aumentar o nível de educação, haverá uma maior conscientização quanto à proteção ao meio ambiente. Vejamos alguns exemplos de ações de sustentabilidade social:

- Ampliação do acesso à Internet para pessoas de baixa renda;

- Implantação de projetos educativos e sociais gratuitos, principalmente para pessoas de baixa renda;

- Implantação de programas voltados para a inclusão social, principalmente de pessoas portadoras de necessidades especiais;

- Implantação de projetos que possibilitem acesso à energia elétrica para pessoas que ainda não possuem este serviço;

- Investimentos em educação pública, visando à qualidade do ensino;

- Investimentos governamentais em saneamento básico, garantindo tratamento de esgoto e acesso à água potável para pessoas que não tem acesso a estes serviços;

- Qualificação profissional de jovens através, principalmente, de cursos gratuitos de língua estrangeira, informática e etc. (Fonte: http://www.suapesquisa.com/religi aosociais/sustentabilidade_social.htm. Acessado em: 18 jul. 2017).

Com isto, percebe-se que vale muito a pena ter uma conscientização social e mais do que isto, que sejam colocados em prática projetos e ações que contemplem o pleno exercício da cidadania.

\section{NOVO CENÁRIO: SUSTENTABILIDADE AMBIENTAL NO CAMPO EMPRESARIAL}

A sustentabilidade ambiental, do ponto de vista empresarial, representa um importante segmento estratégico, cuja correta implantação 
trará grandes vantagens (internos e externos). Para tanto, vamos conhecer a melhor doutrina que conceitua a "sustentabilidade empresarial"?

No entendimento de Celso Funcia Lemme (2010, p. 40), a sustentabilidade empresarial é: "[...] uma etapa na busca pela excelência de gestão, correspondendo ao desafio de ter empresas economicamente viáveis, ambientalmente corretas e socialmente justas".

Trata-se de um conjunto de atitudes que uma pessoa jurídica põe em prática, objetivando o bem cuidar (manutenção) do meio ambiente, além de se preocupar com o desenvolvimento social sustentável.

Com propriedade, segundo Takeshy Tachizawa \& Rui Otávio Bernardes de Andrade (2012, p. 152), as principais estratégias de gestão ambiental e de responsabilidade social, normalmente aplicáveis às organizações deste setor, são:

- Controle, recuperação ou reciclagem das descargas líquidas da atividade industrial;

- Controle ou recuperação de gases e emissões gasosas geradas pelas atividades industriais;

- Desenvolvimento/aperfeiçoamento de sistemas de auditoria ambiental;

- Expansão dos investimentos em controle ambiental;

- Habilitação da organização para rotulagem ambiental;

- Imagem ambiental da empresa para fins de marketing;

- Mudança de composição, desenho e embalagem do produto para tornar seu uso menos danoso à saúde humana e ao meio ambiente;

- Mudanças nos procedimentos de estocagem, transporte, manuseio, logística dos produtos e materiais perigosos;

- Projetos sociais em: meio ambiente, educação, saúde, cultura, apoio à criança e ao adolescente, voluntariado;

- Redução do uso de energia por quantidade de produto fabricado;

- Redução do uso, recuperação ou reciclagem de água por quantidade de produto fabricado; 
- Redução do uso de matérias-primas por qualidade de produto fabricado ou substituição de fonte de energia;

- Disposição adequada de resíduos sólidos e de lixo industrial;

- Reciclagem de sucatas, resíduos ou refugos;

- Seletividade de fornecedores/distribuidores ambientalmente corretos.

Estas estratégias são de especial relevância para uma sustentabilidade ambiental efetiva, real e concreta, trazendo vários dividendos para aquela empresa que, concretamente, aplicar a sustentabilidade ambiental no seu cotidiano.

\subsection{DO SGA - SISTEMA DE GESTÃO AMBIENTAL (ISO 14001)}

Dentro do contexto da sustentabilidade empresarial, a aplicação do Sistema de Gestão Ambiental (SGA) tem um papel importante e necessário numa administração eficiente.

Mas, qual é o conceito de SGA? No conhecimento de Luís Felipe Nascimento et al (2008, p. 208-209): "É o conjunto de procedimentos que irão ajudar a organização a entender, controlar e diminuir os impactos ambientais de suas atividades, produtos e/o serviços".

O SGA pode ser conceituado como a forma inteligente e sustentável de manusear o meio ambiente, com técnicas suficientes para atender a preservação ambiental e às exigências impostas pelas leis, além pelo próprio mercado competitivo.

Agora, já para no entendimento de Maria Suely Moreira (2005, p. 26), o SGA é "um conjunto de procedimentos adotados pela empresa, visando a evitar todo e qualquer tipo de agressão ao meio ambiente e melhorar continuamente seu desempenho ambiental".

Constata-se, nestes conceitos, que o SGA é um instrumento essencial para o manejo equilibrado do meio ambiente, cabendo aos seus responsáveis o papel de implantá-lo nos seus diferentes departamentos e setores corporativos. 
Para facilitar a compreensão do que se apresenta na ISO (Internacional Organization for Standardization) 14001 sobre o conceito de SGA, devem ser considerados, segundo Márcia Martins Mendes De Luca et al (2009, p. 75-76), dentre outros, os seguintes pontos:

- Melhoria contínua por meio do processo de aprimoramento do desempenho ambiental global, considerando a política ambiental estabelecida pela organização;

- Meio ambiente, compreendendo ar, água, solo, recursos naturais, flora, fauna, seres humanos e suas inter-relações;

- Aspectos ambientais, incluindo os elementos das atividades, produtos ou serviços gerados pela organização que podem interagir com o meio ambiente;

- Impacto ambiental, positivo ou negativo, que tenha por origem as atividades, produtos ou serviços da organização;

- Auditoria do SGA, compreendendo o processo sistemático de verificação, executado para avaliar evidências que determinem se está em conformidade com os critérios do sistema definido pela empresa, suas normalidades ambientais internas e a própria legislação ambiental;

- Política ambiental da organização, definindo intenções e princípios em relação ao seu desempenho ambiental global, que prevê uma estrutura para operacionalização do SGA e definição de objetivos e metas ambientais a serem alcançados.

É neste contexto de dinamismo empresarial, que o SGA vem para instrumentalizar as ações corporativas (reduzir os impactos de suas atividades produtivas), com o desafio de equilibrar a relação entre o ser humano, as empresas e o próprio meio ambiente, com o objetivo de se obter um melhor desempenho. 
O tema "responsabilidade social" é bastante amplo, sobretudo se considerado sob o ponto de vista do Brasil, em razão da sua dimensão territorial e populacional, além das suas desigualdades sociais e econômicas. De qualquer forma, para facilitar os nossos estudos, partiremos para a análise dos conceitos dos doutrinadores de renome e relevância acadêmica, mercadológica e social.

Para tanto, vale a pena mencionar a compreensão de Francisco Gomes de Matos (2009), quando conceitua a responsabilidade social como sendo: "[...] uma exigência básica para a atitude e para o comportamento ético, por meio de práticas que demonstrem que a empresa possui uma alma, cuja preservação implica solidariedade e compromisso social". (Fonte: http://www.iacat.com/Revista/recrearte/ recrearte03/etica_socempr.htm. Acessado em: 12 jul. 2017).

Podemos observar, neste conceito, a valorização do planejamento e da preocupação da atuação ética em todos os setores corporativos. Agora, numa ótica específica, ou seja, a responsabilidade social empresarial, propriamente dita, vale transcrever a conceituação firmado pelo Instituto Ethos, quando diz que é:

[...] a forma de gestão que se define pela relação ética e transparente da empresa com todos os públicos com os quais ela se relaciona e pelo estabelecimento de metas empresariais que impulsionem o desenvolvimento sustentável da sociedade, preservando os recursos ambientais e culturais para as gerações futuras, respeitando a biodiversidade e promovendo a redução das desigualdades sociais. (Fonte: http://www1.ethos.org.br/Ethos-

Web/pt/29/o_que_e_rse/o_que_e_rse.aspx. Acessado em: 12 jul. 2017).

Percebe-se, neste raciocínio, uma clara postura de preocupação ambiental, sobrepondo os preceitos éticos e o desenvolvimento sustentável nos diferentes setores da sociedade contemporânea.

Já, em relação ao Conselho Nacional de Indústria (2006, p. 09), a responsabilidade social empresarial pode ser conceituada da seguinte forma: quais as empresas buscam - voluntariamente - 
integrar considerações de natureza ética, social e ambiental às suas interações com clientes, colaboradores, fornecedores, concorrentes, acionistas, governos e comunidades - as chamadas "partes interessadas" visando ao desenvolvimento de negócios sustentáveis.

As corporações devem direcionar os seus esforços para estimular o desenvolvimento da sociedade, por intermédio de ações e projetos que acelerem a sua saúde (alimentícia, educacional, empregatícia, médica, etc), além de explorar e avançar novas pesquisas para otimizar o processo produtivo e a própria qualidade de seus produtos, com vistas ao correto atendimento dos seus clientes.

Além disto, uma empresa que prima pelo exercício constante da "responsabilidade social", tem como prioridade cultivar múltiplos relacionamentos, com o objetivo de gerar produtos competitivos (preços atraentes e com rentabilidade), além da própria qualidade.

Complementando e ressaltando outros aspectos, atualmente, as empresas vivenciam uma posição de escolha intermediária que consiste em respeitar a tríplice realidade das organizações, quais sejam: a econômica, a humana e a social.

No que se refere ao contexto econômico, sem dúvida, a principal meta das pessoas jurídicas (através de seus negócios), é a obtenção de lucro, inserindo sempre a aplicação da ética em todas as suas fases, por exemplo: fabricação, exposição (loja) e venda do produto (consumidor).

Da mesma forma que a realidade econômica, a realidade humana tem o seu valor e importância, pois os atendimentos às necessidades humanas também se fazem presentes, desde o exercício da transparência, ética, até o diálogo e boa-fé entre os envolvidos (humanização).

Já a realidade social visa auxiliar aqueles que passam carências das mais diferentes espécies e dimensões (alimentação, educação, moradia, creche, saúde etc), tendo as ONGs (Organizações Não Governamentais), em parceria com as empresas, um papel de destaque no cenário social.

\subsection{A IMPORTÂNCIA DA RESPONSABILIDADE SOCIOAMBIENTAL DENTRO DO CONTEXTO EMPRESARIAL}


Atualmente, as preocupações são difusas quanto à proteção ao meio ambiente, ou seja, todas as pessoas são responsáveis por este bem tão precioso, inclusive as empresas. Diante disto, podemos abordar e conceituar a responsabilidade socioambiental empresarial, de acordo com o Instituto Ethos (2003, p. 14), como segue:

É a forma de gestão que se define pela relação ética e transparente da empresa com todos os públicos com os quais ela se relaciona e pelo estabelecimento de metas empresariais compatíveis com o desenvolvimento sustentável da sociedade, preservando recursos ambientais e culturais para as gerações futuras, respeitando a diversidade e promovendo a redução das desigualdades sociais. (Fonte: https://www3. ethos.org.br/cedoc/glossario-indicadores-ethos/.

Acessado em: 20 jul. 2017).

Isso quer dizer que a empresa que possuir uma conotação socialmente responsável será aquela considerada capaz de interagir com os personagens que estão em sua volta, como os concorrentes, consumidores, fornecedores, o governo e o próprio meio ambiente.

Sobre o tema, Carla Canepa $(2007$, p. 57) raciocina que o desenvolvimento sustentável se caracteriza como: “[...] um estado fixo de harmonia, mas sim como um processo de mudanças, no qual se compatibiliza a exploração de recursos, o gerenciamento de investimento tecnológico e as mudanças institucionais com o presente e o futuro".

Ter responsabilidade social implica pensar em "desenvolver-se de forma sustentável", em criar estratégias de desenvolvimento econômico em sintonia com as demandas ambientais e sociais, permitindo a satisfação das necessidades atuais sem comprometer a possibilidade das gerações futuras de atenderem seus interesses. Nesse sentido, nos alerta Reinaldo Dias (2010, p. 155), quando afirma que:

[...] os empresários estão se conscientizando de que a empresa não é somente uma unidade de produção e distribuição de bens e serviços que atendem a determinadas necessidades da sociedade, mas que deve atuar de acordo com uma responsabilidade social que se concretiza no respeito aos direitos humanos, na melhoria da qualidade de vida da comunidade e da 
sociedade mais geral e na preservação do meio ambiente natural.

Desta forma, se o desenvolvimento não for sustentável, não se pode afirmar que há desenvolvimento, pois ocorrerá tão somente um crescimento. Enquanto a sociedade não estiver totalmente envolvida, com todas as questões ambientais, só teremos crescimento, com pouco ou nenhum reflexo à proteção dos direitos ambientais e econômicos.

A empresa que se propõe a praticar a responsabilidade socioambiental, deve se atentar com as suas ações (impactos), como bem observa José Pedro Soares Martins (2009, p. 41), quando expõe que:

- Nos colaboradores da empresa, o chamado público interno que movimenta o dia-a-dia da organização;

- Nos fornecedores, de matérias-primas e de vários tipos de insumos que ajudam a empresa a produzir e crescer;

- Nos clientes e consumidores, aqueles que adquirem os produtos e serviços oferecidos pela empresa;

- No meio ambiente, ou seja, a empresa tem muito cuidado na forma de lidar com a água, com a qualidade do ar, com a energia;

- Na comunidade, ou seja, a empresa está preocupada com o desenvolvimento do bairro, da cidade onde está inserida;

- Na sociedade em geral e governo, ou seja, a empresa está muito atenta em cumprir as leis e ajudar no desenvolvimento do país.

E este é um desafio que devemos enfrentar, sob pena de sofrermos enormes consequências, tanto no âmbito ambiental quanto econômico e/ou social. 
Dentro do contexto da sustentabilidade, o cumprimento da legislação (conjunto de leis) também está inserido, e as pessoas físicas e jurídicas devem praticá-las, em especial, no âmbito da proteção ambiental.

Para exemplificar, podemos citar algumas leis federais que visam proteger o meio ambiente, nos seus diferentes aspectos (natural, artificial, cultural e do trabalho), tais como:

\footnotetext{
- Lei $\mathrm{n}^{\circ}$ 6.938/81 - Política Nacional de Meio Ambiente;

- Lei no 9.433/97 - Política Nacional de Recursos Hídricos;

- Lei $\mathrm{n}^{\circ}$ 9.605/98 - Crimes Ambientais e Infrações Administrativas;

- Lei no 9.795/99 - Política Nacional de Educação Ambiental;

- Lei $\mathrm{n}^{\circ}$ 12.305/10 - Política Nacional de Resíduos Sólidos;
}

E, no caso, de uma pessoa (física ou jurídica) que vier a praticar um ilícito ambiental, esta poderá responder juridicamente pelos seus atos, no âmbito administrativo, civil e/ou penal.

Entenda a seguir, no âmbito do direito ambiental empresarial, como funciona a questão da responsabilidade administrativa, civil e penal.

\subsection{RESPONSABILIDADE ADMINISTRATIVA}

A imposição de sanções administrativas, geradas pela ocorrência de atos lícitos ambientais, decorre obrigatoriamente do exercício de um poder próprio da Administração Pública, que é chamado de "poder de polícia".

Assim, é possível que uma pessoa (física ou jurídica) seja responsabilizada administrativamente quando praticar um ato danoso ao meio ambiente. A responsabilidade administrativa por danos ao meio ambiente implica a obrigação fundamental do Estado de cumprir as normas jurídicas ambientais.

No âmbito federal, a infração administrativa ambiental é tratada especificamente pela Lei $n^{\circ}$ 9.605/98, no Capítulo VI (artigos 70 a 76). 
Ressaltamos a importância para o estudo do artigo 72 da Lei $n^{\circ}$ 9.605/98, que determina as modalidades administrativas de punição para as pessoas que infringirem a lei ambiental. Leia e analise cada uma delas:

Artigo 72 - As infrações administrativas são punidas com as seguintes sanções, observado o disposto no art. $6^{\circ}$ :

I - advertência;

II - multa simples;

III - multa diária;

IV - apreensão dos animais, produtos e subprodutos da fauna e flora, instrumentos, petrechos, equipamentos ou veículos de qualquer natureza utilizados na infração;

V - destruição ou inutilização do produto;

VI - suspensão de venda e fabricação do produto;

VII - embargo de obra ou atividade;

VIII - demolição de obra;

IX - suspensão parcial ou total de atividades;

$\mathrm{X}-$ (vetado);

$\mathrm{XI}$ - restritiva de direitos.

Por exemplo: certa construtora agiu irregularmente ao erguer um edifício com andares acima do que a lei permite, como consequência, ela foi responsabilizada administrativa com o embargo da obra e a demolição dos andares excedentes.

\subsection{RESPONSABILIDADE CIVIL}

A responsabilidade civil pelos danos causados ao meio ambiente orienta-se pela teoria da responsabilidade objetiva, segundo a qual, para que o dever de indenizar seja exigido, basta a comprovação da conduta (ação ou omissão), do resultado lesivo e do nexo de causalidade entre um e outro.

Essa responsabilidade está prevista no parágrafo $3^{\circ}$ do art. 225 da Constituição Federal de 1988, bem como no parágrafo $1^{\circ}$ do artigo 14 da Lei ${ }^{\circ} 6.938 / 81$ e, ainda, no art. $3^{\circ}$ da Lei $n^{\circ} 9.605 / 98$. 
Por exemplo: por causar danos ambientais (emissão de gases tóxicos) ao entorno da empresa (vizinhança), esta foi condenada a pagar como indenização a quantia de $\mathrm{R} \$ 10.000,00$ (Dez mil reais) por cada pessoa lesada. Lembrando que, como toda ação judicial, o acusado/condenado tem o direito à defesa e ao contraditório.

\subsection{RESPONSABILIDADE PENAL}

Outra forma muito efetiva de se prevenir e combater os danos ao meio ambiente é pela aplicação de sanções penais (a base legal é a Lei $\mathrm{n}^{\circ}$ 9.605/98) para aqueles que estiverem envolvidos em atividades que possam causar ou causem danos ao meio ambiente.

Porém quem poderá ser responsabilizado, caso um crime seja praticado por uma empresa (pessoa jurídica)? São aqueles que constam no art. $2^{\circ}$ da Lei $n^{\circ} 9.605 / 98$, ou seja:

Quem, de qualquer forma, concorre para a prática dos crimes previstos nesta Lei, incide nas penas a estes cominadas, na medida da sua culpabilidade, bem como o diretor, o administrador, o membro de conselho e de órgão técnico, o auditor, o gerente, o preposto ou mandatário de pessoa jurídica, que, sabendo da conduta criminosa de outrem, deixar de impedir a sua prática, quando podia agir para evitá-la.

E quais são essas punições? Para as pessoas jurídicas, estão no artigo 21 da Lei $n^{\circ}$ 9.605/98, como segue:

- multa;

- restritiva de direitos:

a) suspensão parcial ou total da atividade;

b) interdição temporária de estabelecimento, obra ou atividade;

c) proibição de contratar com o poder público ou dele receber benefícios;

- prestação de serviços à comunidade:

a) custeio de programa e de projetos ambientais;

b) execução de obras de recuperação de áreas degradadas; 
c) manutenção de espaços públicos;

d) contribuições a entidades ambientais ou culturais públicas.

Por exemplo: certa empresa praticou um crime ambiental, tipificado pelo artigo 54 (Causar poluição) da Lei dos Crimes Ambientais, para tanto, por este ato ilícito foi condenado ao pagamento de uma multa de $\mathrm{R} \$$ 100.000,00 (Cem mil reais), além de se tornar impedido de contratar com o poder público ou dele receber quaisquer benefícios.

Dependendo das circunstâncias (atenuantes ou agravantes), o juiz poderá aumentar ou diminuir a sentença para aquele que cometer um crime ambiental, conforme dispõem os artigos 14 e 15 da Lei no 9.605/98. Para tanto, são circunstâncias que atenuam (diminuem) a pena (artigo 14):

I - baixo grau de instrução ou escolaridade do agente; II - arrependimento do infrator, manifestado pela espontânea reparação do dano, ou limitação significativa da degradação ambiental causada;

III - comunicação prévia pelo agente do perigo iminente de degradação ambiental;

IV - colaboração com os agentes encarregados da vigilância e do controle ambiental.

Por exemplo: com o objetivo de economizar o descarte de resíduos sólidos, a empresa dispensava estes elementos no terreno baldio em frente a sua própria empresa. Porém, através de uma denúncia anônima, a empresa infratora foi condenada por 3 anos e 6 meses, mas por ter se arrependido e de forma espontânea a reparação do dano gerado, recebeu uma atenuância da dosimetria da pena para apenas 3 anos. tigo 15):

Agora, são circunstâncias que agravam (aumentam) a pena (ar-

I - reincidência nos crimes de natureza ambiental;

II - ter o agente cometido a infração:

a) para obter vantagem pecuniária;

b) coagindo outrem para a execução material da infração;

c) afetando ou expondo a perigo, de maneira grave, a saúde pública ou o meio ambiente;

d) concorrendo para danos à propriedade alheia; 
e) atingindo áreas de unidades de conservação ou áreas sujeitas, por ato do Poder Público, a regime especial de uso;

f) atingindo áreas urbanas ou quaisquer assentamentos humanos;

g) em período de defeso à fauna;

h) em domingos ou feriados;

i) à noite;

j) em épocas de seca ou inundações;

1) no interior do espaço territorial especialmente protegido;

m) com o emprego de métodos cruéis para abate ou captura de animais;

n) mediante fraude ou abuso de confiança;

o) mediante abuso do direito de licença, permissão ou autorização ambiental;

p) no interesse de pessoa jurídica mantida, total ou parcialmente, por verbas públicas ou beneficiada por incentivos fiscais;

q) atingindo espécies ameaçadas, listadas em relatórios oficiais das autoridades competentes;

r) facilitada por funcionário público no exercício de suas funções.

Por exemplo: os proprietários de uma mineradora foram condenados, criminalmente, a 4 anos de prisão, pela prática de crime de poluição, tipificado pelo artigo 54, parágrafo segundo, item I da Lei $\mathrm{n}^{\circ}$ 9.605/98.

\section{CONSIDERAÇÕES FINAIS}

Através desse artigo, foi possível analisar uma importante novidade no setor privado, qual seja a Sustentabilidade Empresarial, demonstrando seus principais pontos, positivos e negativos, e as principais repercussões nos dias de hoje. É louvável o objetivo do tema, que viabiliza uma discussão acerca da utilização consciente e moderada do meio ambiente e seus recursos naturais, através da adoção de um modelo de desenvolvimento sustentável. Restou demonstrado que para que o paradigma da sustentabilidade seja implantado e eficaz, é necessária uma ação conjunta e coordenada, que passará pela participação de cidadãos, empresas e governos. 
Ressalta-se que apesar da dificuldade em adotar esse novo pensamento, devido ao alto custo e grandes alterações estruturais e organizacionais, as empresas privadas devem investir e se tornar cada vez mais sustentáveis. Isto porque são responsáveis pelos impactos e danos vierem a causar.

Desta forma, é importante frisar e exaltar os benefícios que a adoção de ações empresariais mais sustentáveis irá trazer, para o dia a dia da empresa. As vantagens abrangem não apenas os aspectos sociais e ambientais, mas também econômicos e financeiros, de maneira que traz inovação e perenidade para os negócios, gerando a oportunidade de trabalhar em um novo mercado e atividade, através de ações inovadoras de ecoeficiência.

Até há pouco tempo, a preocupação com o meio ambiente se limitava em cumprir as normas previstas na legislação para que as empresas pudessem trabalhar sem que fossem incomodas. De algum tempo para cá, a responsabilidade tornou-se mais ampla e rigorosa, sendo cobrada não apenas pelo poder público, mas também pela população, que, muitas vezes, se confunde com o consumidor final do produto da empresa. Assim, perante um cliente mais exigente, consciente e atento ao que consome e a forma como é produzido o que lhe é oferecido, as empresas se veem obrigadas a adotar uma posição mais responsável no que se refere à utilização de recursos naturais.

No presente artigo, para que fosse compreendido o verdadeiro significado de Sustentabilidade Empresarial, foi necessário contextualizar e passar por uma breve conceituação de termos como desenvolvimento sustentável e sustentabilidade para que chegássemos à aplicabilidade do novo paradigma.

Salienta-se que apesar das limitações apontadas, há uma significativa evolução e adoção das novas atitudes na vida empresarial. Nesse cenário, este estudo constatou que nem tudo o que está previsto de fato ocorre na prática, mas cada vez mais vem sendo feito um trabalho de informação e conscientização que visa à redução dos impactos ambientais, a promoção de programas sociais que mantêm a empresa economicamente viável e competitiva no mercado.

Percebe-se, ao final, ser incontroverso que aquele empreendimento que investir em sustentabilidade empresarial colherá os frutos em um futuro próximo, uma vez que cada vez mais a tendência é prezar pela preservação do meio ambiente, dirimindo impactos, inclusive para garantir 
a sobrevivência da raça humana com qualidade de vida. Para tal, frisa-se que só é capaz de praticar a sustentabilidade empresarial aquela empresa que investe em ações ambientais e possui uma boa gestão ambiental, estando intimamente ligadas as três dimensões, quais sejam, sociais ambientais e econômicas.

\section{REFERÊNCIAS BIBLIOGRÁFICAS}

BARBIERI, José Carlos; CAJAZEIRA, Jorge Emanuel Reis. Responsabilidade social empresarial e empresa sustentável. $3^{a}$ ed. São Paulo: Saraiva, 2016.

BAUMAN, Zygmunt. Vidas Desperdiçadas. Rio de Janeiro: Jorge Zahar Editor, 2005.

CANEPA, Carla. Cidades Sustentáveis - o Município Como Locus da Sustentabilidade. São Paulo: RCS Editora, 2007.

DE LUCA, Márcia Martins Mendes; CORRÊA, Denise Maria Moreira Chagas; SILVA, Francisca Regiane Chaves da; OLIVEIRA, Marcelle Colares. A Auditoria Ambiental como Instrumento Gerencial de Apoio à Preservação do Meio Ambiente. In: Sociedade, Contabilidade e Gestão. Rio de Janeiro, v. 4, n. 2, jul/dez 2009.

DERANI, Cristiane. Direito Ambiental Econômico. $3^{\text {a }}$ ed. São Paulo: Saraiva, 2008.

DIAS, Reinaldo. Sustentabilidade - origem e fundamentos; educação e governança global; modelo de desenvolvimento. São Paulo: Atlas, 2015.

FIORILLO, Celso Antonio Pacheco. Curso de Direito Ambiental Brasileiro. 17 ed. São Paulo: Saraiva, 2017.

; Conte, Christiany. Crimes Ambientais $2^{\text {a }}$ ed. São Paulo: Saraiva, 2017.

FREITAS, Juarez. Sustentabilidade - Direito ao futuro. $2^{\text {a }}$ ed. São Paulo: Forum, 2012.

LEMME, Celso Funcia. O valor gerado pela sustentabilidade corporativa. In: LINS, Clarissa; Zylbersztajn, David. Sustentabilidade e Geração de Valor - A Transição para o Século XXI. Rio de Janeiro: Campus, 2010.

MACHADO, Paulo Affonso Leme. Direito Ambiental Brasileiro. 24 ed. São Paulo: Malheiros, 2016.

MOREIRA, Maria Suely. Pequeno Manual de treinamento em sistema de gestão ambiental. Nova Lima: INDG tecnologia e Serviços Ltda, 2005.

NASCIMENTO, Luis Felipe; LEMOS, Ângela Denise da Cunha; MELO, Maria Celina Abreu. Gestão Socioambiental estratégica. Porto Alegre: Bookman, 2008.

RODRIGUES, Marcelo Abelha. Direito Ambiental Esquematizado. São Paulo: Saraiva, 2017. 
SANTOS, Rita da Conceição Coelho Loureiro. Sustentabilidade Recíproca do Meio Ambiente Ecológico com o Meio Social. In: SANTOS, Rita da Conceição Coelho Loureiro (Organizadora). O Meio Ambiente em Facetas... São Paulo: Baraúna, 2011.

SANTOS, Luiz Dario dos. Ética empresarial, responsabilidade social e sustentabilidade. São Paulo: Polo Books, 2017. A concretização do direito humano de acesso aos recursos hídricos: com ênfase a uma vida digna e saudável no Brasil. São Paulo: Polo Books, 2016. - Relação de Consumo Sustentável: A geração de resíduos sólidos sob a ótica da proteção jurídica do consumidor. São Paulo: Letras Jurídicas, 2015.

STEFANIAK, Jeaneth Nunes. A insustentabilidade ambiental no capitalismo. São Paulo: GZ Editora, 2016.

TACHIZAWA, Takeshy; ANDRADE, Rui Otávio Bernardes de. Gestão Socioambiental: estratégias na nova era da sustentabilidade. $2^{\mathrm{a}}$ ed. São Paulo: Campus, 2012.

\section{SITES}

http://www.iacat.com/Revista/recrearte/recrearte03/etica_soc-empr.htm. Acessado em: 12 jul. 2017.

http://www1.ethos.org.br/EthosWeb/pt/29/o_que_e_rse/o_que_e_rse.aspx. Acessado em: 12 jul. 2017.

http://www.atitudessustentaveis.com.br/sustentabilidade/sustentabilidade/. Acessado em: 16 jul. 2017.

http://www.atitudessustentaveis.com.br/artigos/sustentabilidade-ambiental-desenvolvimento-e-protecao/. Acessado em: 17 jul. 2017.

http://www.pensamentoverde.com.br/meio-ambiente/conceito-e-definicao-desustentabilida-ade-ambiental/. Acessado em: 17 jul. 2017.

http://www.suapesquisa.com/religiaosociais/sustentabilidade_social.htm. Acessado em: 18 jul. 2017.

https://www3. ethos.org.br/cedoc/glossario-indicadores-ethos/. Acessado em: 20 jul. 2017. 